\title{
Dones, trajectòries de vida i noves ruralitats
}

\author{
Isabel Salamaña
}

Universitat de Girona. Departament de Geografia

isabel.salamana@udg.edu

Mireia Baylina

M. Dolors Garcia Ramon

Universitat Autònoma de Barcelona. Departament de Geografia

mireia.baylina@uab.cat

mariadolors.garcia.ramon@uab.cat

\section{Ana María Porto}

Universidad de Santiago de Compostela. Departamento de Métodos de Investigación y

Diagnóstico en Educación

anamaria.porto@usc.es

\section{Montserrat Villarino}

Universidad de Santiago de Compostela Departament de Geografia montserrat.villarino@usc.es

\section{Resum}

En el marc d'un cert retorn al camp per part d'alguns col-lectius i en determinats territoris, dones formades s'instal.len en aquests entorns rurals i des de la seva posició contribueixen a construir la ruralitat actual. Aquest és un fenomen nou a diverses àrees rurals d'Espanya i d'Europa i frena la tendència d'un procés sostingut de despoblament rural selectiu quant a edat $\mathrm{i}$ gènere que ha afectat negativament les dones joves. Aquest article pretén donar a conèixer la trajectòria de vida d'algunes dones de Catalunya i Galícia que han decidit viure en entorns rurals i que resideixen al mateix municipi, comarca o província on van néixer. Ens interessa saber què els ha portat a viure al món rural i si aquesta permanència o tornada al lloc d'origen té a veure amb motius familiars, laborals o socioambientals que puguin il-lustrar la tendència d'aquestes noves ruralitats. De forma expressa, relacionem la seva trajectòria de mobilitat residencial amb el nivell d'estudis i l'ocupació laboral. L'estudi constata que els aspectes socioambientals i emocionals són importants en el retorn i corrobora que, amb igualtat de formació acadèmica, hi ha diferències d'oportunitats segons el grau de ruralitat.

Paraules clau: dones; ruralitat; mobilitat residencial; formació; Catalunya; Galícia 


\section{Resumen. Mujeres, trayectorias de vida y nuevas ruralidades}

En el marco de un cierto retorno al campo por parte de algunos colectivos y en determinados territorios, mujeres formadas se instalan en el medio rural y desde su posición contribuyen a construir la ruralidad actual. Este es un fenómeno nuevo en diversas áreas rurales de España y Europa que frena la tendencia de un proceso sostenido de despoblamiento rural selectivo en cuanto a la edad y al género que ha afectado negativamente a las mujeres jóvenes. Este artículo pretende dar a conocer la trayectoria de vida de algunas mujeres de Cataluña y Galicia que han decidido vivir en entornos rurales y que residen en el mismo municipio, comarca o provincia donde nacieron. Nos interesa saber qué las ha llevado a vivir en el medio rural y si esta permanencia o vuelta al lugar de origen se relaciona con motivos familiares, laborales o socioambientales que puedan ilustrar la tendencia de las nuevas ruralidades. De forma expresa, relacionamos la trayectoria de movilidad residencial de las mujeres con su nivel de estudios y la ocupación laboral. El estudio constata que los aspectos socioambientales y emocionales son importantes en el retorno y corrobora que, con igualdad de formación académica, hay diferencias de oportunidades según el grado de ruralidad.

Palabras clave: mujeres; ruralidad; movilidad residencial; formación; Cataluña; Galicia

\section{Résumé. Femmes, trajectoires de vie et nouvelles ruralités}

Dans le cadre d'un certain retour au champ de la part de certains groupes et sur des territoires déterminés, des femmes formées s'installent en milieu rural et contribuent depuis leur position à bâtir la ruralité actuelle. Il s'agit d'un phénomène nouveau dans plusieurs zones rurales de l'Espagne et de l'Europe qui freine la tendance d'un processus soutenu de dépeuplement rural sélectif en ce qui concerne l'âge et le genre et qui a négativement affecté les femmes jeunes. Cet article souhaite faire connaître la trajectoire de vie de quelques femmes de la Catalogne et de la Galice qui ont décidé d'habiter dans des environnements ruraux et qui résident dans la même commune, région ou province où elles sont nées. Nous cherchons à savoir ce qui les a amenées à vivre dans un milieu rural et si cette permanence ou retour au lieu d'origine est liée à des motifs familiaux, professionnels ou socio-environnementaux qui puissent illustrer la tendance des nouvelles ruralités. Nous associons expressément la trajectoire de mobilité résidentielle des femmes avec leur niveau d'études et leur profession. L'étude constate que les aspects socio-environnementaux et émotionnels sont importants dans ce retour et ce qui confirme que, à avec une formation académique similaire, il existe des différences d'opportunités selon le degré de ruralité.

Mots-clés: femmes; ruralité; mobilité résidentielle; Catalogne; Galice

\section{Abstract. Women, life journeys and new ruralities}

In the context of a certain 'back to the countryside' move on the part of certain groups and in specific geographic areas, educated women are settling in the rural environment and from this position are helping to build the new rurality. This is a new phenomenon, seen in several rural areas of Spain and other countries in Europe, which is slowing down a sustained process of rural depopulation, selective in terms of age and gender, that has negatively affected young women. This article aims to illustrate the life journeys of some women from Catalonia and Galicia who have made the choice to live in rural areas, in the same municipality, county or province where they were born. Our aim is to ascertain, first, what factors have led them to live in the rural environment and, second, whether their return to their place of origin is related to family, work or social and environmental 
reasons, which could give us an insight into the way in which the new ruralities are being shaped. We explicitly relate women's paths of residential mobility to their level of education and their occupation. The study reveals that socio-environmental and emotional factors are important in the desire to return and it indicates that, given equal educational backgrounds, there are differences in opportunities depending on the degree of rurality of the different areas.

Keywords: women; rurality; residential mobility; education; Catalonia; Galicia

\section{Sumari}

\section{Introducció}

2. Context territorial de les zones d'estudi

3. Lloc d'origen i de residència de les dones entrevistades

4. Viure on van néixer i desplaçaments residencials
5. Mobilitat residencial de les dones i qualificació acadèmica

6. Conclusions

Agraïments

\section{Introducció}

Des de la darreria del segle xx, la immigració, la revitalització econòmica i el desenvolupament de les infraestructures i els serveis han transformat bona part de les zones més poblades i millor comunicades del món rural del nostre país (Hoggart i Paniagua, 2002; García i Sánchez, 2005; Morén i Solana, 2006; Guirado, 2011; García, 2011; Bayona i Gil, 2013). Tot això sense deixar de banda les profundes transformacions que ha experimentat el món rural des de fa dècades i que ja s'han fet estructurals, amb diferències segons els territoris: el fet que l'agricultura hagi passat a un segon pla com a activitat econòmica principal, l'envelliment i el sobreenvelliment de la població, o la solteria i la sobremasculinitat adulta, per exemple, que són fets que perduren.

A les àrees més dinàmiques és una realitat la transposició de la vida urbana al camp, la diversificació econòmica, la industrialització de l'agricultura que perviu $\mathrm{i}$, en general, l'elevat grau d'interconnexió econòmica a escala mundial (Aldomà, 2015; Woods, 2007, 2011). Els darrers anys, marcats per la crisi econòmica, no han trasbalsat aquesta situació però sí que n’han forçat alguns aspectes, per exemple l'interès per una economia i gestió ambiental i social més integrades i equilibrades, una dimensió social i col-laborativa de l'economia local, o una autonomia i capacitats d'iniciativa rurals (Aldomà, 2015). Segons Nogué (2016), la crisi està canviant la manera de relacionar-nos amb els territoris i, en el procés de retrobament amb els llocs, el món rural adquireix un nou paper. Això explica un cert retorn al camp, un nou neoruralisme que es caracteritza per l'experimentació d'una nova forma de territorialitat, més vinculada a les emocions, que genera al capdavall noves pràctiques socioes- 
pacials (Nogué, 2016; Halfacree, 2006, 2007). Hi ha una petita agricultura, d'explotacions familiars o de nouvinguts al camp (força joves), que explota de manera més diversa i integrada els recursos locals i contribueix a la reactivació o manteniment de la ruralitat (Aldomà, 2015), es reinventen antigues professions $\mathrm{o}$ es recuperen zones rurals marginals a través de projectes econòmics $\mathrm{o}$ culturals de qualitat (Nogué, 2016).

En aquest marc, algunes dones formades es queden o s'instal.len en aquests entorns rurals i des de la seva posició contribueixen a construir la ruralitat actual. Aquest és un fenomen nou a diverses àrees rurals d'Espanya i d'Europa i frena la tendència, des de fa dècades, d'un procés sostingut de despoblament rural selectiu quant a edat $\mathrm{i}$ gènere que ha afectat negativament les dones joves (Fademur, 2009; Forsberg i Stenbacka, 2013; Wiest, 2016). Aquest fenomen és d'especial rellevància quan tots els estudis sobre la societat rural han convingut a afirmar que les dones són imprescindibles per a la sostenibilitat social i econòmica d'aquests territoris (Sabaté, 1992; Garcia Ramon i Baylina, 2000; Little, 2001; Pallarès-Barberà et al., 2003; Goverde et al., 2004; Camarero, 2009; Sampedro, 2009; MARM, 2011).

Aquest article pretén donar a conèixer la trajectòria de vida d'algunes dones que han decidit viure en entorns rurals i que resideixen al mateix municipi, comarca o província on van néixer. Ens interessa saber què els ha portat a viure al món rural (del qual han estat expulsades sistemàticament) i si aquesta permanència o tornada al lloc d'origen té a veure amb motius familiars, laborals o socioambientals que puguin il.lustrar la tendència d'aquestes noves ruralitats. De forma expressa, relacionem la seva trajectòria de mobilitat residencial amb el nivell d'estudis i l'ocupació laboral.

La recerca, que forma part d'un projecte més ampli ${ }^{1}$, $s^{\prime}$ inspira en el marc conceptual proposat per Halfacree (2006), que considera que la vida quotidiana en el medi rural és un dels tres pilars en què se sustenta el triple model de l'espai rural. Aquest model conceptualitza la ruralitat com una construcció social en la qual els aspectes materials (el lloc), les pràctiques (la vida quotidiana) $\mathrm{i}$ els aspectes imaginats (les representacions) s'interrelacionen dinàmicament. Els discursos de les dones sobre la seva vida quotidiana informen de la ruralitat actual i s'han de comprendre mediatitzats pel lloc on viuen i per les representacions formals del món rural.

L'estudi s'ha realitzat sobre la base d'una metodologia qualitativa i etnogràfica a partir d'entrevistes en profunditat fetes a seixanta dones que viuen en el món rural de Catalunya (trenta dones de les comarques de l'Alt Urgell, el Baix Empordà i la Conca de Barberà) i de Galícia (trenta dones de les comarques d'Ulloa, el Sar i el Morrazo). La selecció de les entrevistades s'ha fet a partir de contactar amb persones de les àrees d'estudi, algunes conegudes de les investigadores, $\mathrm{i}$ amb personal tècnic dels governs locals o regionals ocupat en

1. Mujeres, trabajo y ruralidad: estrategias innovadoras para un desarrollo profesional y personal (2011-0004-INV-00024). Instituto de la Mujer, Ministerio de Sanidad, Política Social e Igualdad. 
temes d'igualtat de gènere o de desenvolupament rural. $S$ 'ha demanat a aquestes persones intermediàries noms de dones amb educació superior que hagin decidit d'establir-se professionalment en el món rural, siguin o no originàries d'aquests territoris. Tot i que les primeres dones entrevistades van suggerir noms d'altres dones conegudes per entrevistar, hem prioritzat la inclusió de dones recomanades per diversos intermediaris a fi de diversificar més la mostra.

La majoria de les dones han nascut a la zona, tot i que moltes han viscut a la ciutat en algun moment del seu trajecte de vida. Es tracta de dones d'entre trenta i cinquanta anys majoritàriament, moltes amb estudis universitaris, casades o amb parella heterosexual i majoritàriament amb fills. Més de la meitat de les dones són gerents de la seva pròpia empresa o autònomes, i la majoria treballen en el sector serveis seguit del sector agrari. Les dones no es perceben com a "dones rurals» en un sentit tradicional, sinó que més aviat es perceben com a «dones urbanes que viuen en l'entorn rural» (Baylina et al., 2016) i expressen, gairebé de forma unànime, que la facilitat en la mobilitat quotidiana és una condició prèvia per viure en el medi rural.

Les entrevistes aborden molts aspectes sobre els espais i temps de la seva vida quotidiana, amb especial atenció a l'esfera del treball en sentit ampli. Es tracta la seva formació acadèmica i professional, la trajectòria laboral, les responsabilitats en el treball domèstic i de cura, el treball voluntari, la conciliació laboral i familiar, els temps i espais de lleure, l'ús de les noves tecnologies, la mobilitat residencial i quotidiana, les dificultats en la implementació dels seus projectes professionals i les expectatives laborals i vitals futures. També s'han recollit les opinions de les dones sobre la ruralitat i el futur econòmic i social dels territoris rurals, els efectes de la crisi econòmica i financera dels darrers anys en aquests espais i els avenços en matèria d'igualtat de gènere. En aquest article ens centrarem principalment en el relat que fan de la seva mobilitat residencial fins a arribar al lloc rural on es troben ara.

Entenem per moviment residencial els desplaçaments vinculats a la mobilitat per raó d'estudi, de treball o d'altres (per exemple, per matrimoni o parella) dins la pròpia comarca o província; desplaçaments que normalment no provoquen un desarrelament del lloc on viu la seva família, els amics, les xarxes socials, etc. Quan el canvi de residència s'ha produït a una província diferent de la d'origen i ha significat una estada perllongada perquè s'ha enllaçat, per exemple, estudis-treball, el considerem un moviment migratori. La tornada al lloc d'origen l'entenem com un moviment de retorn.

\section{Context territorial de les zones d'estudi}

Un element geogràfic ens apropa a Catalunya i Galícia, i és que en ambdós llocs la majoria de la població viu vora el mar. Les zones litorals o properes a aquestes n'han determinat de manera extraordinària els assentaments de població a causa del procés de metropolitanització en els darrers setanta anys. A mesura que ens allunyem de les terres litorals, la forta petjada urbana va minvant, però la frontera entre el món urbà i el rural no és nítida. El creixement 
urbà de dispersió ha configurat paisatges híbrids de característiques urbanes i rurals fragmentades, una llarga i ampla franja de transició que ens condueix cap als extensos territoris rurals.

Acceptant que les formes de vida urbana de la població han penetrat arreu, també hem d'acceptar que en els territoris híbrids i rurals les maneres de viure, per a les petjades històriques i les textures del seu medi, hi prenen característiques diferents.

Les característiques de poblament i d'organització de l'espai rural de Galícia és un tema complex i discutit a causa de la seva peculiar morfologia i distribució. Com diu Sánchez Pardo (2013: 76), la disposició del poblament: esquitxat entre espais de conreu i muntanya, formant petits raïms i aglomeracions, normalment no gaire compactes i estesos al llarg de les valls i vessants, fa que sovint no es pugui establir un límit exacte entre un assentament i l'altre. Es fa difícil explicar-ne les formes i trames i definir i delimitar la unitat bàsica de població; tot plegat fa que prendre el municipi com a unitat d'anàlisi en dificulti la comprensió. A Catalunya no és que no hi hagi una complexa i rica heterogeneïtat d'assentaments de població; el model territorial difús, caracteritzat per una alta mobilitat pendular i el desenvolupament d'un ampli espectre de noves activitats disseminades pel territori, ha donat lloc a una estructura d'assentaments expansiva que ha arribat a les zones rurals.

Prenent com referència la definició de l'Atles de la nova ruralitat de Catalunya (Aldomà, 2009), els territoris amb cinquanta habitants per quilòmetre quadrat representen la ruralitat més inequívoca. Els de cent habitants per quilòmetre quadrat presenten un grau de ruralitat important, i els municipis de cinc mil i deu mil habitants compten amb àrees de baixa densitat, però la presència d'un nucli o fet urbà és molt més destacada i determinant. A Catalunya, l'Alt Urgell i la Conca de Barberà són clarament de predomini rural, amb una densitat de $14,4 \mathrm{~h} / \mathrm{km}^{2}$ i $31 \mathrm{~h} / \mathrm{km}^{2}$, respectivament. El Baix Empordà, amb una densitat de 203,6 h/ $\mathrm{km}^{2}$, té divuit municipis amb menys de $50 \mathrm{~h} / \mathrm{km}^{2} \mathrm{i}$ sis municipis amb menys de $100 \mathrm{~h} / \mathrm{km}^{2}$, que abasten el $61,9 \%$ de la superfície de la comarca. A Galícia, com s'ha explicat, prendre el municipi com a entitat de referència en desdibuixa el grau de ruralitat i urbanització. La Clasificación dos concellos e parroquias segundo o grao de urbanización ${ }^{2}$ classifica la comarca del Morrazo, amb una densitat de $549,9 \mathrm{~h} / \mathrm{km}^{2}$, amb quatre municipis que acullen disset parròquies, les quals aglutinen uns dos-cents nuclis de població, de contínuum rururbà, on hi ha tretze zones ZIP (zones de població

2. L'Institut Gallec d'Estadística (IGE) classifica els municipis i les parròquies segons el grau d'urbanització atenent al seu caràcter urbà o rural, i n'estableix tres categories a partir de les àrees locals $(\mathrm{AL})$ i de la seva densitat de població. Zones densament poblades (ZDP): conjunt contigu d'àrees locals (AL) de densitat superior a $500 \mathrm{~h} / \mathrm{km}^{2}$ i una població total per a la zona d'almenys 50.000 habitants; zones intermèdies (ZIP): són el conjunt d'AL que no pertanyen a una zona densament poblada i on cadascuna té una densitat superior a $100 \mathrm{~h} / \mathrm{km}^{2}$, o bé la població total de la zona és superior a 50.000 habitants, o bé és adjacent a una zona densament poblada, i zones poc poblades (ZPP): són els grups d'àrees locals (AL) clarament rurals. 
intermèdia) altes (semiurbanes-rurals), nou ZIP baixes (zona intermèdia ruralsemiurbana, menys del $50 \%$ de la població viu en zones rurals) i vuit ZIP rurals (més del $50 \%$ de la població viu en zones rurals). A la comarca del Sar, de les vint parròquies, set són classificades de ZIP baixa, zona intermèdia amb municipis rurals-semiurbans, i nova ZPP, zones rurals. A la comarca d'Ulloa, les noranta-vuit parròquies són classificades com a ZPP, zones rurals.

Podem concloure que el Baix Empordà i el Morrazo, atenent al seu grau d'urbanització, són comarques intermèdies, amb una alta diversitat de poblaments: municipis urbans, semiurbans-rurals, semirurals-urbans $\mathrm{i}$, alhora, municipis rurals. Comarques amb una frontera física urbà-rural molt desdibuixada. La resta de comarques, atenent a la classificació del grau d'urbanització, són clarament rurals, sobretot l'Alt Urgell i Ulloa, i d'una manera més matisada les comarques de la Conca de Barberà i del Sar perquè hi ha alguns nuclis que podem definir com a intermedis (rurals-semiurbans).

\section{Lloc d'origen i de residència de les dones entrevistades}

Les figures 1 i 2 ens mostren uns escenaris distints entre Catalunya i Galícia en relació amb els moviments realitzats en el trajecte de vida de les seixanta dones que resideixen a les zones rurals estudiades. En el cas de Catalunya, els fluxos d'origen de les dones són més complexos; per contra, a Galícia són d’una simplicitat extraordinària.

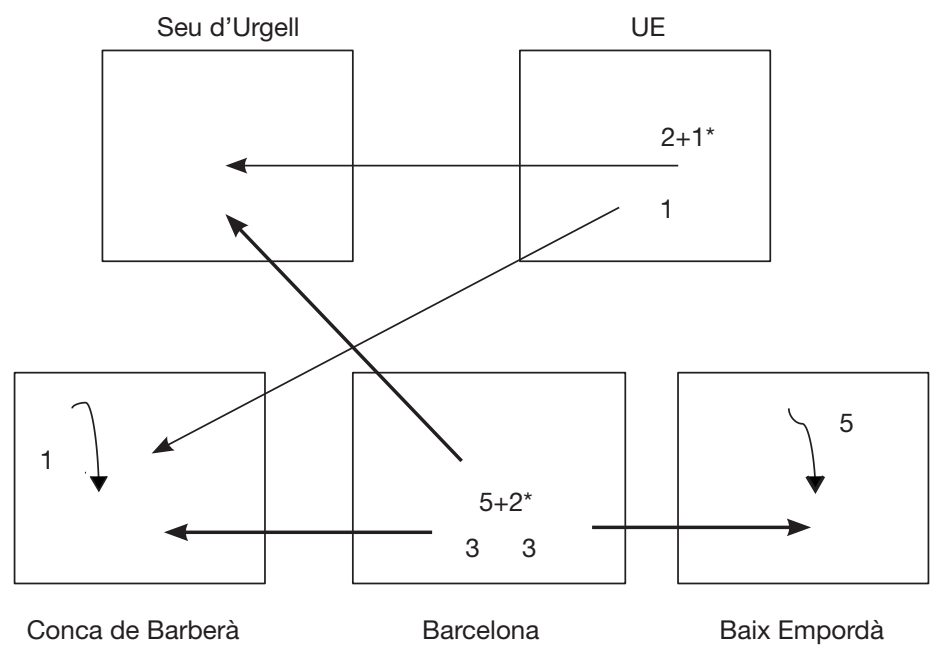

Figura 1. Moviments per canvis residencials i moviments migratoris de les dones entrevistades a Catalunya.

* Moviments de retorn de dones nascudes a la comarca.

Font: elaboració pròpia. 




Morrazo

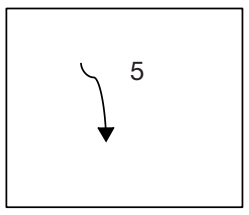

O Sar

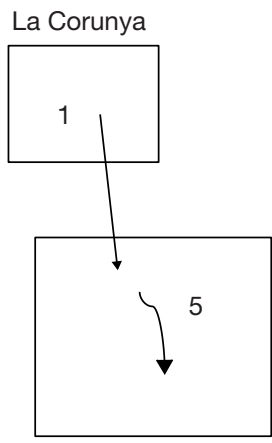

Ulloa

Figura 2. Moviments per canvis residencials municipals o parroquials i moviments migratoris de les dones entrevistades de Galícia.

Font: elaboració pròpia.

A Catalunya, setze de les trenta dones entrevistades han emprès un procés migratori. En relació amb la immigració, destaca versemblantment la comarca més pirinenca, l'Alt Urgell, bressol de fortes emigracions protagonitzades històricament per mà d'obra jove i en especial femenina, que ha deixat un espai envellit i força masculinitzat (Solé, 2013: 155). L'arribada d'aquestes dones cal contextualitzar-la correctament perquè, per la data d'arribada i la seva trajectòria de vida, no sembla anar relacionada amb l'arribada de nous residents que es registra a la comarca a partir de la dècada dels anys vuitanta, població jove activa, sense vincle previ, que busca el contacte amb la natura, la pràctica d'esport, la vida senzilla o un estil de vida alternatiu (Guirado, 2011). Dues dones procedents de Barcelona i una d'Anglaterra hi arriben per qüestió de matrimoni/parella, i una, procedent també de Barcelona, per feina. Tres dones, com comentarem més endavant, són clarament migracions de retorn, dones d'edat adulta, professionalment actives, que han trobat oportunitats laborals favorables que els han facilitat el retorn. Altres tres dones, que hi arriben en períodes diferents, busquen una qualitat de vida millor. Només una dona, que va arribar-hi l'any 2006, respondria al perfil de població nouvinguda que busca un estil de vida alternatiu (Guirado, 2011).

Vam viure molt de temps a Sant Cugat [...] ens vam enamorar de la vall i de la comarca. Des que vam comprar la casa fins que vam prendre la decisió [d'anar a viure-hi] van passar uns cinc anys. Vam dir: «Per què no?». Vam decidir fer una formatgeria a Josa, però en el moment que ella [...] decideix plegar ens vam posar tots d'acord per tirar endavant el Serrat Gros. (Maria, 1963, administració, formatgera i copropietària d'una formatgeria, Alt Urgell) ${ }^{3}$

3. Tots els noms de les persones entrevistades han estat canviats per garantir-ne l'anonimat. 
I dues dones, una de Suïssa i l'altra de Barcelona, podríem relacionar-les amb el fenomen neorural registrat als anys setanta, com bé van documentar i analitzar Martínez Illa (1987) i Nogué (1988).

Nosaltres vam arribar aquí el 1979. Ell va acabar Físiques i jo vaig acabar Magisteri. Ell tenia claríssim que volia venir a viure a la muntanya; jo feia poc que anava amb ell i, com a parella, vam decidir venir a viure aquí. Va ser una opció de vida. Jo tenia 23 anys i ell en tenia 25 . La gent del poble deia: «I aquests vindran aquí i es guanyaran la vida? I ara!». [...] vam haver de fer més d'una cosa per guanyar-nos-la [...] vam començar fent patates de llavor i ara faig melmelades, en tinc a la botiga 67 varietats. (Neus, 1956, mestra, artesana de melmelades, Alt Urgell)

L'anàlisi dels motius de les setze dones catalanes que han arribat a les tres zones d'estudi de Catalunya ens revela que nou dones (sis a l'Alt Urgell, una a la Conca de Barberà i dues al Baix Empordà) van prendre la decisió d'emigrar mancomunadament amb la parella (i de manera pactada, les que en tenen, amb els fills), i el motiu del desplaçament va ser cercar una qualitat de vida millor. Altrament, set dones (quatre de l'Alt Urgell, dues de la Conca de Barberà i una del Baix Empordà) van arribar-hi per motius de matrimoni o de parella. En aquests casos, la majoria de les dones tenen alguna relació familiar amb la comarca (la resposta més habitual que donen és: «els estius els passàvem aquí») o són dones que hi han arribat per raó de la feina de la parella.

Vaig néixer a Barcelona, vaig estudiar a Saragossa i vaig tornar a Barcelona per treballar. Ell va decidir de muntar un centre veterinari amb altres companys per donar serveis a l'Empordà i al Gironès; són un grup de veterinaris rurals. Ens vam casar i jo vaig decidir que volia tenir una família nombrosa i no estava disposada a pujar i baixar cada dia [des de Barcelona]. Vaig fer oposicions, les vaig aprovar i vaig decidir venir a viure aquí dalt. (Ariadna, 1969, veterinària, coordinadora de acció agrícola del Departament d'Agricultura, Ramaderia i Pesca, Baix Empordà)

Una situació ben diferent és la que observem a Galícia. Una comunitat històricament caracteritzada per les migracions rurals amb altes pèrdues de població jove i femenina, que té poca immigració extraterritorial. Per les seves particularitats, i en ser majoritàriament moviments residencials, seran analitzades més endavant.

\section{Viure on van néixer i desplaçaments residencials}

Com explica Solana (2000), un canvi de residència no té —o té d'una manera mínima - un impacte sobre la vida de la persona, sobre el seu entramat de relacions i sobre la societat. L'anàlisi de la trajectòria de vida del conjunt de dones entrevistades que resideixen al municipi, comarca o província assenyala que el $75 \%$ viuen on van néixer (taula 1). El 60\% d'aquest conjunt de dones se situa en el tram d'edat denominat "generació suport»(Camarero, 2009). 
Taula 1. Dones entrevistades que resideixen al municipi o comarca/província on van néixer

\begin{tabular}{lccccc}
\hline & Després de 1980 & $\mathbf{1 9 7 0 / 7 9}$ & $\mathbf{1 9 6 0 / 1 9 6 9}$ & $\mathbf{1 9 5 0 / 5 9}$ & $\%$ \\
\hline Alt Urgell & & 2 & 1 & & 30 \\
Conca de Barberà & 2 & 2 & 2 & 2 & 60 \\
Baix Empordà & 3 & 3 & 2 & & 70 \\
Morrazo & & 2 & 2 & 1 & 100 \\
O Sar & 1 & 2 & 6 & 4 & 100 \\
Ulloa & 6 & 15 & 17 & 7 & 90 \\
Total dones & & & & & (45 dones) \\
& & & &
\end{tabular}

Font: elaboració pròpia.

Es tracta de dones nascudes entre els anys 1962 i 1982, que l'any 2012 tenien entre trenta i cinquanta anys i que per la seva posició en el cicle de vida són el grup de població més activa, la que suporta, com explica Camarero (2009), la major càrrega de treball productiu i de reproducció en el medi rural.

La taula 1 ens informa de les diferències importants entre Galícia i Catalunya, vinculades, com hem explicat, a la diferència de fluxos migratoris registrats a ambdues comunitats. Quasi totes les dones estudiades a les zones de Galícia resideixen al lloc on va néixer.

Una primera hipòtesi és que a les parròquies escollides hi ha pocs moviments migratoris extraterritorials i que els moviments immigratoris de dones procedents d'altres províncies o de l'exterior de Galícia aquí són molt baixos. Només una de les dones entrevistades va néixer en una província diferent de la que actualment viu. Tanmateix, hi ha una qüestió interessant en relació amb els moviments residencials que va relacionat amb la multiplicitat d'escales en el sentiment de pertinença dels habitants del món rural gallec. Com explica Sánchez Pardo (2013), «quan es pregunta a un gallec d'on és, pot començar referint-se al casal X i passar després a situar-lo al lloc X, al llogaret X, a la parròquia X, fins a arribar a esmentar la comarca X». Quan analitzem el cas de les set dones que han canviat de residència per matrimoni, observem que la distància entre el lloc d'origen i el de destinació és extraordinàriament molt curta i, efectivament, s'explica perquè les dones han pres com a lloc de referència la parròquia. És a dir, que si prenem com a lloc de referència el municipi, el nombre de desplaçaments interiors és molt menor. Malgrat el baix recorregut territorial, el que sí que queda clar és la preferència, més obligada que volguda, de residir al lloc d'origen dels homes, una realitat molt comuna al món rural. Observem també dos moviments per raons de treball i un que podríem qualificar de moviment migratori de retorn. Aquest darrer va vinculat al desig de tenir cura de la família, però, alhora, de crear una empresa que permeti una certa flexibilitat per adaptar-se a la maternitat sense descuidar la professió.

Fui directora de proyectos en una agencia de publicidad de la que era socia [...] Ahora mismo estoy más centrada en mi vida personal [...]. Poder conciliar mi 
trabajo — arrancar el nuevo negocio — con la vida personal — mi bebé. Uno de los motivos de volver al pueblo era ese: poder cuidar de mis mayores cuando tocara, cuidar de mi bebé, disfrutar de la familia, estar cerca de mis padres [...]. Eso me da sensación de bienestar. (Claudia, 1974, llicenciada en Publicitat i Diplomada en Periodisme, copropietaria d'una llibreria, el Morrazo)

La biografia de les dones gallegues és més complexa i alhora molt interessant quan analitzem la decisió de viure al lloc on van néixer. A la taula $2 \mathrm{hem}$ anotat com a "opció» els motius del canvi de residència de quatre dones de la comarca d'Ulloa. Totes les dones van néixer al lloc de residència actual, per raons familiars en van marxar, van fer una estada més o menys perllongada a la ciutat per raons d'estudi, i totes hi han tornat per mantenir el patrimoni agrícola i cultural familiar i en algun cas el pazo. Tres dones són llicenciades en Ciències Econòmiques, una en Farmàcia i, juntament amb dues dones també llicenciades en Ciències Econòmiques que sempre han viscut a la mateixa parròquia, han emprès activitats relacionades amb l'agricultura i la ramaderia ecològiques, amb l'hoteleria i el turisme rural, amb la producció de galetes, amb l'elaboració de castanyes, etc. Són dones que van iniciar els seus projectes a partir de l'any 1995. Una d'elles, en ser preguntada sobre com definiria la comarca d'Ulloa, sintetitza molt bé el sentir d'aquestes persones, que es refereixen al món rural amb un fort contingut ideològic, i al qual tornen després d'una decisió i elecció voluntàries (Nogué, 2016):

Un diamante en bruto. Aquí hay algo que atrapa. Hay muchísima gente que ha venido un día de visita y se ha quedado a vivir. Cada vez hay más extranjeros que vienen. Hay una energía telúrica; el río más antiguo de España nace aquí, el Ulla... El Camino de Santiago... Aquí confluyen todos los caminos de Europa, en Melide... Hay algo... Hay algo muy fuerte. Hay algo de ruralidad pero también hay gente muy urbanita que ha venido a vivir aquí [...] Hay algo urbanita, pero con una ruralidad brutal paisajísticamente hablando. Y todo lo que tenemos aquí: el río Ulla, el castillo de Pambre, todas las iglesias románicas, los petroglifos... Y en cuanto al mundo empresarial también es una

Taula 2. Motius del canvi de residència intermunicipal i moviments de retorn de les dones que resideixen a la mateixa comarca/província on van néixer

\begin{tabular}{lccccccc}
\hline & $\begin{array}{c}\text { Menys } \\
\text { de } 5 \text { anys }\end{array}$ & De 6 a 10 & De 10 a 15 & De 16 a 20 & De 21 a 25 & Més de 25 \\
\hline Alt Urgell & $\mathrm{R}(\mathrm{C})$ & & $\mathrm{R} \mathrm{R}$ & & & \\
Conca de Barberà & $\mathrm{C}$ & T A & $\mathrm{C}$ & $\mathrm{C}$ & & \\
$\begin{array}{l}\text { Baix Empordà } \\
\text { Morrazo }\end{array}$ & $\mathrm{RT}$ & $\mathrm{T}$ & & $\mathrm{C}$ & $\mathrm{C}$ & $\mathrm{T}$ \\
$\begin{array}{l}\text { O Sar } \\
\text { Ulloa }\end{array}$ & & & & & $\mathrm{C} \mathrm{C}$ & C C C \\
\hline
\end{tabular}

$\mathrm{R}$ (retorn), T (treball), C (matrimoni o parella), O (opció), A (altres motius).

Font: elaboració pròpia. 
comarca muy interesante. (Mar, 1971, llicenciada en Ciències Empresarials, grangera, propietària d'una granja i d'una galeteria, Ulloa)

Com es pot observar en aquesta citació, les dones expressen una relació estreta entre les persones i el seu entorn biosocial; tenen una concepció de la natura, dels recursos i del paisatge més àmplia, són més sensibles a la cura, al respecte $\mathrm{i}$ a la protecció de l'entorn. D'altra banda, també reivindiquen el reconeixement social i econòmic de la dona en el desenvolupament rural i són realistes en relació amb el que vol dir viure i treballar en aquest medi. Saben que les activitats convencionals tenen un futur difícil, que la formació és imprescindible, i que emprendre projectes innovadors en el món rural comporta riscos.

Queremos que nuestra comarca se conozca, queremos ponerla en valor; darle un valor y que nos visualicen, sobre todo a las mujeres que estamos trabajando aquí, que no siempre nos reconocen. (Carlota, 1967, llicenciada en Farmàcia, agricultora, propietària d'una empresa de plantes medicinals, Ulloa)

A pesar de que hay gente que vuelve, lo veo muy duro porque no hay facilidades reales. Es duro para vivir; o tienes que ser emprendedor o no tienes trabajo. Eso siempre es un riesgo: ya no solo es vivir en el campo, sino también ser emprendedor en el campo... Y eso es un riesgo. (Mariña, 1969, llicenciada en Ciències Econòmiques, propietària d'una casa rural, Ulloa)

A Catalunya, com hem vist, la casuística és lleugerament més complexa en relació amb els moviments migratoris. A l'Alt Urgell, la pèrdua de capital humà de dones acadèmicament qualificades és un fet ben documentat (Pallarès-Barberà et al., 2003; Pallarès-Blanch, 2014). Una de les dones entrevistades ho exemplifica molt bé:

Hi ha una noia que és farmacèutica a Andorra; una altra és inspectora dels Mossos a Barcelona; una altra va estudiar Econòmiques i treballa a Sabadell; una altra també va estudiar Econòmiques i és directora de banc a Andorra. (Muriel, 1973, llicenciada en Dret, directora dels projectes Leader a l'Alt Urgell i la Cerdanya, responsable de promoció econòmica del Consell Comarcal de l'Alt Urgell, Alt Urgell)

Tanmateix, l'Alt Urgell és alhora una comarca receptora de dones qualificades; en el nostre estudi, totes les dones que han retornat són llicenciades. Es tracta de dones que després de viure uns anys fora de la comarca han emprès el camí de retorn i és interessant llegir-hi el desig de tornar vinculat a la qualitat de vida i a l'enyorança dels seus paisatges:

Em vaig traslladar de la Guàrdia a la Seu per anar a escola; de la Seu a Barcelona per anar a la universitat. Em van donar una beca per anar a fer classes d'espanyol a Anglaterra. Anava tot molt bé i m'hi hauria pogut quedar facilment... Però jo volia viure aquí i vaig decidir tornar. Amb el meu marit ens vam conèixer a Anglaterra ell va venir aquí. I, com a mi, li va semblar un paradís. (Rosanna, 1969, llicenciada en Filologia Anglesa, empresària de turisme rural, Alt Urgell) 
El Baix Empordà, com explica Solana (2000), «és una terra de pas i d'assentament per a un gran nombre de persones vingudes d'altres contrades de Catalunya, de la resta d'Espanya i, cada vegada més, de l'estranger. La creixent valorització dels seus paisatges i els seus pobles les situa en el punt de mira de la possible construcció de noves residències i urbanitzacions. Els municipis rurals es converteixen prioritàriament en espais de residència però no de producció». Ben segur que cal situar l'alta permanència residencial de les dones entrevistades dins aquest context $\mathrm{i}$, com explicarem més endavant, relacionada també amb les oportunitats laborals de la comarca. Recollint, també, les observacions de Solana (2000), «la recuperació "física" dels pobles i la rehabilitació del patrimoni residencial ve acompanyada per un encariment progressiu de l'habitatge, que si bé per una banda revalora el seu patrimoni, pot incidir negativament sobre altres sectors de la població, en aquest cas especialment en la població jove d'aquests pobles, que no té capacitat per accedir a aquests habitatges».

La Tallada és tan petit que tenim 450 habitants entre tots quatre pobles. Sempre he viscut aquí, però tinc un lapse de deu anys de la meva vida en què vaig viure a Bellcaire $[\ldots]$ Per gust mai no hauria marxat, però era impossible perquè no hi havia res per comprar [referint-se a cases] [...] La meva opció era quedar-m'hi perquè m'agradava molt, però no hi havia res i hem hagut d'esperar molts anys per tenir-ne l'oportunitat. [...] Vaig sondejar un senyor que, probablement, no m'ho hauria venut mai [la casa] que tenia una estructura d'una casa començada que l'havia deixat empantanegada perquè ja es veia venir que vindrien mal dades. (Diana, 1969, doctora en Enginyeria Agrícola y màster en Ciències Polítiques, investigadora de l'Institut de Recerca i Tecnologies Agroalimentàries [IRTA], Baix Empordà)

Segons la nostra opinió, a la Conca de Barberà, el motiu dels baixos moviments de canvis de residència va vinculat al fet que cinc de les set dones entrevistades viuen a Montblanc, on les oportunitats de treball han estat força més favorables que per a les dones que viuen als pobles petits de la comarca, amb una ruralitat molt més accentuada.

Montblanc és una mica difícil dir que és món rural. És rural perquè és una estructura urbanística petita, però personalment no ens hi veiem gaire perquè gaudim del que té la ciutat i de moltíssimes coses que tenim al voltant. Per a nosaltres és una sort; estem a mitja hora d'oblidar-nos del món i a tres quarts d'hora de la platja. Tens la muntanya aquí i la platja allà... Ho tenim tot [...] i un avantatge important: una família al costat que t’ajuda. (Rita, 1967, mestra de música i directora d'escola, Conca de Barberà)

\section{Mobilitat residencial de les dones i qualificació acadèmica}

La majoria de les dones entrevistades han realitzat un o més canvis de residència al llarg de la seva vida i, en alguns casos, un procés de migració.

Com es pot veure a la taula 3 , del total de dones que resideixen al lloc on van néixer, 32 tenen estudis superiors. Observem un nivell més alt d'estudis 
Taula 3. Lloc on han fet estudis superiors les dones que resideixen al municipi o comarca/ província on van néixer

\begin{tabular}{|c|c|c|c|}
\hline & Llocs on han realitzat estudis & Nombre de llocs & Nombre de dones \\
\hline \multirow[t]{3}{*}{ Alt Urgell } & Barcelona & 3 & 3 \\
\hline & Bèlgica & 2 & \\
\hline & Anglaterra & 1 & \\
\hline \multirow[t]{2}{*}{ Conca de Barberà } & Barcelona & 4 & \\
\hline & Tarragona & 1 & $\begin{array}{c}\text { (1 no estudis } \\
\text { superiors) }\end{array}$ \\
\hline \multirow[t]{4}{*}{ Baix Empordà } & Barcelona & 5 & 7 \\
\hline & Girona & 5 & \\
\hline & Tarragona & 1 & \\
\hline & Xile & 1 & \\
\hline \multirow[t]{3}{*}{ Morrazo } & Santiago & 6 & 10 \\
\hline & Coruña & 1 & (4 no estudis \\
\hline & Vigo & 1 & superiors) \\
\hline O Sar & Santiago & 4 & $\begin{array}{c}10 \\
\text { (6 no estudis } \\
\text { superiors) }\end{array}$ \\
\hline \multirow[t]{3}{*}{ Ulloa } & Santiago & 6 & 9 \\
\hline & Madrid & 1 & (3 no estudis \\
\hline & Londres & 1 & superiors) \\
\hline
\end{tabular}

Font: elaboració pròpia.

entre les dones catalanes (de les 16 dones entrevistades, només una no té estudis superiors). Per contra, a Galícia el nombre de dones amb estudis superiors és menor (de les 29 dones, només 15 tenen estudis superiors) i el nivell més baix de qualificació és a la comarca del Sar (del total de 10 dones entrevistades, 6 no tenen estudis universitaris). Totes les dones amb qualificació acadèmica van viure uns anys de la seva vida fora del municipi de residència actual. En quatre casos les dones van fer estades per motius d'estudis a l'estranger. L'estratègia familiar del món rural de dotar d'estudis les filles com a capital social d'accés professional pren unes connotacions interessants perquè és un retorn de capital social, professional i de vivències de gran valor en tornar al seu lloc d'origen.

A casa ens van obligar a tots a estudiar, a treballar, a sortir fora, a viure a fora, a veure món... Vaig estudiar a Girona, vaig treballar en un operador turístic alemany, també en una central de reserves hoteleres com a directora comercial d'una cadena d'hotels, i ara estic a l'àrea de promoció de la província de Girona i promocionem tant la Costa Brava com els Pirineus. (Abril, 1976, diplomada en Turisme, treballadora del departament de màrqueting del Patronat de Turisme de Girona, Baix Empordà)

Viví hasta los trece años en Monterroso y luego tuve que irme a estudiar fuera. Viví un año en Orense y después estuve en Lugo cinco años. Después estuve 
Taula 4. Sectors d'activitat on treballen les dones residents al municipi, comarca o província on van néixer

\begin{tabular}{lccccccc}
\hline & & & \multicolumn{5}{c}{ Agricultura/ } \\
& Comerç & Sanitat & Educació & rural & Indústria Innovació Administració \\
\hline Alt Urgell & & & & 1 & & 1 & 1 \\
Conca de Barberà & 1 & 1 & $2\left(1^{*}\right)$ & 1 & & 1 \\
Baix Empordà & & & 1 & 1 & 1 & 4 \\
Morrazo & $2\left(1^{*}\right)$ & $2\left(2^{*}\right)$ & 1 & $1^{*}$ & & 1 \\
O Sar & $2^{*}$ & & 3 & $4\left(3^{*}\right)$ & & & $1^{*}$ \\
Ulloa & & & & $6\left(2^{*}\right)$ & $3\left(1^{*}\right)$ & & \\
\hline
\end{tabular}

* Nombre de dones sense estudis superiors

Font: elaboració pròpia.

un año en Santiago y volví aquí [a Monterroso]. (Carolina, 1969, llicenciada en Ciències Empresarials, tècnica de gestió en una empresa serradora familiar, Ulloa)

L'experiència d'estudiar fora del lloc de residència i en molts casos d'adquirir bagatge professional a la ciutat afavoreix indiscutiblement l'intercanvi de coneixements, permet un anar i venir, una sortida i un retorn, l'equilibri entre la seguretat i l'aventura, de manera que allò inèdit no destrueix allò familiar, sinó que l'enriqueix, i allò habitual no prohibeix la innovació sinó que l'estimula (Marín, 2012). Vivències i experiències que poden ajudar a promoure iniciatives socioeconòmiques al lloc de residència.

Vaig marxar, com tots aquí, per estudiar a la Universitat Autònoma de Barcelona. Vaig estudiar dret i l'últim any vaig fer un Erasmus a la Universitat de Lieja; [...] i un any més per fer un postgrau de dret europeu a la mateixa universitat. Després vaig començar a buscar feina i vaig treballar en un despatx d'advocats de Barcelona [...]. Em va sortir una feina a Lleida i vaig estar quatre anys al Patronat Català Pro-Europa. I vaig tornar aquí. (Muriel, 1973, llicenciada en dret, directora dels projectes Leader a l'Alt Urgell i la Cerdanya, responsable de promoció econòmica del Consell Comarcal de l'Alt Urgell, Alt Urgell)

Certament, hi ha una diversitat de perfils de dones, atenent a la seva formació acadèmica o professional, que enriqueixen l'escenari cada vegada més divers, complex i multifuncional del món rural.

En el conjunt de dones hem comptat fins a 22 llicenciatures diferents. Ens sembla important assenyalar-ho per l'estesa segregació horitzontal relacionada amb l'elevada presència de dones en ocupacions i llocs de treballs amb menor reconeixement social $\mathrm{i}$ econòmic, $\mathrm{i}$ en els quals les possibilitats de promoció professional són limitades. Onze dones són llicenciades en carreres tipificades com a masculines: enginyeries de telecomunicacions i electrònica, alimentària, tècnica agrícola i forestal, ciències econòmiques i empresarials, física i química; nou han cursat carreres amb un grau més alt de barreja per sexes: medicina, 
farmàcia, dret, comunicació audiovisual i ciències polítiques; i dotze han fet estudis més feminitzats: filologia, belles arts, psicologia, pedagogia, història, infermeria, magisteri i graduat social. Una diversitat no gens menyspreable. Quan correlacionem la formació acadèmica adquirida i la seva ocupació, la diversitat en resulta interessant. Hem corroborat que hi ha un grup important de dones que desenvolupen la seva activitat d'acord amb la seva formació acadèmica (21 de les 32). Quan parlem de correlació cal advertir que moltes dones ocupen llocs de treball a l'Administració pública (serveis) i que d'altres treballen com a autònomes en empreses pròpies, és a dir, d'autoocupació; per tant, no podem deduir d'aquestes dades que hi hagi una equiparació horitzontal o vertical de gènere. La diferència entre Catalunya i Galícia també és important. En les dones catalanes hi ha una correlació formació-ocupació (11 de 16 dones); a Galícia la relació és lleugerament més baixa (10 de 16 dones). La menor correlació la trobem a la comarca d'Ulloa, perquè, com s'ha explicat, 4 dones formades acadèmicament amb estudis superiors han emprès el camí d'innovar amb temes relacionats amb el desenvolupament rural.

La major correlació la trobem al Baix Empordà i, tot i que en menor grau, al Morrazo, ambdues comarques, en termes territorials de ruralitat, més híbrides, perquè és on hi ha un major grau de diversitat econòmica i una urbanització més elevada. En tots dos casos hi ha dones que tenen empreses pròpies, treballadores autònomes que exploren nínxols d'ocupació innovadors $\mathrm{i}$ interessants.

Decidí montar una empresa de servicios lingüísticos [...]. Me veía un poco limitada [...]. Entonces empecé a meterme en temas de internet y me empezaron a salir trabajos de redacción de artículos [...] me requería una formación técnica y decidí tener una titulación oficial, un posgrado de Community Management virtual por la Universidad de Barcelona y por la Business School [...] estoy tranquila en el sentido de que estoy formada y adecuada para desarrollar mi profesión. (Rosa, 1981, llicenciada en Filologia Gallega, gestora de comunicació virtual, el Morrazo)

Al Baix Empordà, com explica Solana (2000), ens trobem davant d'un espai rural —en aquest cas, l'Empordanet- en el qual s'aprecien no només tendències cap a una especialització residencial sinó també una elitització social a causa del seu prestigi històric i paisatgístic. Els llocs de treball tendeixen a la concentració en les dues ciutats principals, la Bisbal i Torroella, i també a Girona. Aquest procés és especialment palès en els sectors professionals de més qualificació, en els quals hi ha els nivells de mobilitat obligada residencial-treball de més intensitat. Aquesta constatació sembla afirmar-se en les dones entrevistades, ja que, excepte una dona que treballa a la seva pròpia explotació agrària, totes es desplacen cada dia per anar a treballar, a la comarca o a Girona, en activitats diverses: una fa d'enginyera electrònica en un viver d'empreses, una altra treballa en màrqueting turístic i una altra fa d'investigadora a l'Institut de Recerca i Tecnologies Agroalimentàries (IRTA). Malgrat això, no ens atrevim a parlar de treballats elititzats, però sí en mols casos d'un alt grau d'especialitat. 
Quan vaig començar treballava exclusivament d'investigadora en l'àmbit de l'enginyeria de processos [...]. I des de fa uns tres anys vaig acceptar fer de cap. Ara estic totalment immersa i perduda en la gestió d'un grup de recerca de vint investigadors, cinc o sis doctorands i sis o set tècnics. O sigui, que ara és com una bogeria. (Diana, 1969, doctora en Enginyeria Agrícola i màster en Ciències Polítiques, investigadora de l'IRTA, Baix Empordà)

Immobilitat residencial i no tenir estudis superiors no significa no ser emprenedora. En aquest sentit, és molt interessant conèixer com moltes dones s'han anat formant a partir de la professió fent cursos de formació per emprendre projectes, com, per exemple, un centre de dia al Morrazo, una escola bressol al Sar o un centre d'educació especial i un centre especial de treball a la Conca de Barberà. Iniciatives, sense cap mena de dubte, imprescindibles per millorar el benestar i la qualitat de vida de la població i que contribueixen a fixar població, a generar ocupació i a articular el territori rural.

Vaig fer comerç, després vaig fer secretariat de direcció i finalment vaig fer el batxillerat... La meva primera filla té síndrome de Down. Una professora em va dir que una associació de pares volia crear una escola d'educació especial. [...] L'Ajuntament ens va cedir un terreny, vam començar amb $600 \mathrm{~m}^{2}$, després 2.000 i després 2.500; i ara en tenim 4.700 a Montblanc i 2.500 a la Selva del Camp. En vint-i-cinc anys! Vam començar el 1986! (Coloma, 1951, batxillerat, comerç i secretariat de direcció, gerent d'un centre d'educació especial i d'un centre especial de treball, Conca de Barberà)

Igualment és interessant veure que hi ha dones pageses de famílies tradicionals que promouen projectes de productes relacionats amb la riquesa agrícola de la comarca. Es tracta d'iniciatives que busquen el reconeixement en els mercats, qualitat i no quantitat de producte, que fugen dels grans circuits comercials i que controlen la producció, l'envasament i la comercialització a partir de crear cooperatives agràries.

Cuando empezamos a hacer esto [la pimentera], me ilusioné muchísimo... Estoy muy satisfecha [...] Quería hacer algo más en esta vida... No quería llegar al final de mi vida y preguntarme: «¿Qué hice?» [...]. Yo veía que podía llegar más lejos, que tenía la capacidad para hacer más. En el año 2006 montamos la sociedad y soy la presidenta. (Miriam, 1960, batxillerat, pebrotera, presidenta de A Pementeira, SAT, el Sar)

Si es consulta la web de la cooperativa A Pementeira ${ }^{4}$, podrem veure que, a més de la dinàmica en termes de producció i d'innovació en la comercialització dels pebrots d'Herbón, amb certificació europea de denominació d'origen protegida, de les 23 persones que van fundar la societat agrària de transformació, 20 són dones.

4. <https://www.lospimientosdepadron.com/es/>. 
Certament, la formació és un requisit important per a les dones, però els estudis superiors no són l'únic camí per accedir al treball o per emprendre projectes. L'adquisició de formació al llarg de la vida, les característiques personals i la predisposició són fonamentals per explorar els recursos i les potencialitats del territori, i moltes de les dones del món rural en són un bon exemple.

\section{Conclusions}

Acceptant que les formes de vida urbana han entrat arreu, no podem obviar que el món urbà i el rural s'organitzen de manera diferent. Les dones rurals no se senten identificades amb els tòpics tradicionals que s'han atribuït tant als territoris rurals com a la població que hi viu, perquè la seva vida no difereix essencialment de la del món urbà. Fer aflorar el perfil sociodemogràfic, ric i heterogeni dels territoris rurals és imprescindible per contextualitzar-ne bé el teixit social. La història de vida de les dones rurals ens permet conèixerne la diversitat i posar-ne en valor les diferències. El seu reconeixement exigeix reivindicar i garantir la justícia de gènere en termes de drets socials i econòmics.

Els contextos territorials analitzats no només són diferents entres si - Catalunya i Galícia—, sinó que també hi ha importants contrastos dins els mateixos territoris rurals segons el major o menor grau de ruralitat. Alhora, les dones també responen a perfils diferents. Aquest article ha pretès conèixer-les a partir d'analitzar la seva trajectòria de vida relacionant la mobilitat residencial i el grau de formació acadèmica. S'ha fet palès que hi ha diferències importants entre ambdues comunitats autònomes i dins de cadascuna, i hem confirmat que amb igualtat de formació acadèmica hi ha diferències d'oportunitats segons el grau de ruralitat.

La tornada al lloc d'origen de les dones amb estudis acadèmics superiors és deguda principalment a la voluntat de mantenir el patrimoni familiar, vinculat a un fort sentiment de pertinença, molt visible en el cas de Galícia, i a la cerca d'una millor qualitat de vida i a l'enyorança d'uns paisatges determinats, en el cas de Catalunya. Per tant, es corrobora la idea d'un retorn al camp molt vinculat a l'experimentació d'una nova connexió amb el territori, més emocional. A Catalunya, les possibilitats de realització laboral són també un factor que explica la fixació d'aquestes dones al camp (la majoria hi han trobat oportunitats laborals més favorables). És evident que la tornada d'aquestes dones enriqueix els territoris rurals, obre mentalitats, introdueix innovacions i pot estimular la creativitat.

En les zones de ruralitat més híbrida (cas del Baix Empordà i del Morrazo), hi ha una correlació més alta entre el perfil de la formació acadèmica adquirida i la seva ocupació, sigui com a treballadores assalariades o autoocupades creant la seva pròpia empresa. En el cas del Baix Empordà, la tendència cap a una especialització residencial dels municipis rurals lligada a una major qualificació dels sectors professionals està portant a una mobilitat obligada residènciatreball de forta intensitat. Recollint el terme automobility d'Urry (2004), les 
dones autoorganitzen la seva mobilitat de manera privada, fet que els permet la inserció laboral sense trencar amb les seves arrels identitàries.

A la zones més rurals de Galícia hi un grau més alt d'autoocupació de dones amb nivell d'estudis superiors. Es tracta, en alguns casos, de dones que han tornat al seu lloc d'origen per mantenir el patrimoni agrícola i cultural familiar i emprendre activitats que contribueixin a promoure el desenvolupament endogen de la comarca. Això no treu que siguin molt coneixedores de les dificultats d'innovar i dels riscos que comporta l'emprenedoria al món rural.

Resseguint les biografies de les dones, hem pogut veure que la immobilitat residencial i una baixa formació acadèmica no necessàriament són sinònims d'immobilitat innovadora. Són moltes les dones que han trencat la barrera de gènere i de context social per promoure activitats que contribueixin al benestar i la qualitat de vida de la població rural; o pageses de famílies més tradicionals que han emprès iniciatives que busquen el reconeixement en els mercats a partir de la singularitat i la qualitat dels seus productes.

Hem analitzat les trajectòries vitals de dones inquietes, emprenedores, que han decidit desenvolupar el seu projecte personal i professional en el món rural i ens informen d'algunes de les noves ruralitats actuals. La majoria han decidit lliurement viure-hi, d'altres hi han anat a parar per raó de matrimoni o de parella, i són moltes les que en valoren la qualitat de vida com un dels trets diferencials del món rural. Les dones escollides no representen la diversitat de perfils i això explica que, en l'anàlisi del treball que realitzen, no s'hi recullin termes negatius com l'atur, la manca d'incentius o l'exclusió social.

La permeabilitat rural-urbana és un fet i és necessària, i l'entorn rural és avui un atractiu per a la població urbana. No obstant això, és important no deixar-lo en mans de processos d'intensificació exògena que posin en perill un desenvolupament equilibrat en tots els sentits. Les polítiques públiques s'han d'encaminar a promoure activitats econòmiques i de serveis que reconeguin l'activitat professional i la funció social de les persones que hi viuen i hi treballen. I en aquest capital humà, el paper de les dones i el seu reconeixement social és fonamental per vertebrar la societat rural i garantir la sostenibilitat del territori.

\section{Agraïments}

Les autores agraeixen a les dones entrevistades la seva bona disposició, col-laboració i informació facilitada. Sense elles, aquest estudi no hauria estat possible.

\section{Referències bibliogràfiques}

Aldomà, Ignasi (2009). Atles de la nova ruralitat. Fundació del Món Rural. En línia.

- (2015). Atles de la nova ruralitat. L'actualitat del món rural. Els anys de la gran crisi a la Catalunya rural 2008-2015. Fundació del Món Rural. En línia.

Bayona, Jordi; GiL, Fernando (2013). «Is foreign immigration the solution to rural depopulation? The case of Catalonia (1996-2009)». Sociologia Ruralis, 53 (1), 26-50. 
Baylina, Mireia; Garcia Ramon, Maria Dolors; Porto, Ana María; Salamaña, Isabel; Villarino, Montserrat (2016). "Women assess rurality. A tailored rural idyll». A: Karin Wiest (ed.). Women and migration in rural Europe. Labour markets, representations and policies. Basingstoke: Palgrave Macmillan, 25-43.

Camarero, L. (coord.) (2009). La población rural de España. De los desequilibrios a la sostenibilidad. Barcelona: Fundació la Caixa. Estudis Socials 27. En línia.

Fademur (2009). Mujeres rurales en España. Anuario de la Fundación de Estudios Rurales. Unión de Pequeños Agricultores y Ganaderos, 61-77.

García, B. (2011). Ruralidad emergente, posibilidades y retos. Madrid: Ministerio de Medio Ambiente, Medio Rural y Marino.

García, A.; SÁnchez, D. (2005). La población rural en Catalunya: entre el declive y la revitalización. Cuadernos Geográficos, 36, 387-407.

Forsberg, G.; Stenbacka, S. (2013). «Mapping gendered ruralities». European Countryside, 1, 1-20.

Garcia Ramon, M. D.; Baylina, M. (eds.) (2000). El nuevo papel de las mujeres en el desarrollo rural. Vilassar de Mar: Oikos-Tau.

Goverde, H.; Haan, H. de; Baylina, M. (eds.) (2004). Power and gender in European Rural Development. Aldershot: Ashgate.

Guirado, C. (2011). Tornant a la muntanya. Migració, ruralitat $i$ canvi social al pirineu català: el cas del Pallars Sobirà. Bellaterra: Universitat Autònoma de Barcelona. Departament de Geografia. Tesi doctoral. En línia.

Halfacree, K. (2006). «Rural space: constructing a three-fold architecture». A: P. Cloke, T. Marsden i P. Mooney (eds.). Handbook of rural studies. Londres: Sage, 63-90.

- (2007). "Still surprises in store: Revisiting the ordinary in rural geography». Documents d'Anàlisi Geogràfica, 50, 87-103.

Hoggart, K.; Paniagua, A. (2002). «The restructuring of rural Spain?». Journal of Rural Studies, 17, 63-80.

LitTle, J. (2001). Gender and rural geography. Identity, sexuality and power in the countryside. Harlow: Prentice Hall.

Marín, F. (2012). "Identitat, territori i mobilitat: apunts per a una antropologia de la immigració». Revista de Psicologia, Ciències de l'Educació i de l'Esport. Aloma 30 (2), 13-22. En línia.

Ministerio de Medio Ambiente y Medio Rural y Marino (2011). Diagnóstico de la igualdad de género en el medio rural. Madrid.

Martínez Illa, S. (1987). "Utopia, espai i migracions utòpiques. El "retorn al camp" ". Documents d'Anàlisis Geografica, 11, 61-69.

Morén, R.; Solana, M. (2006). "La immigració en àrees rurals i petites ciutats d'Espanya. Un estat de la qüestió». Documents d'Anàlisi Geogràfica, 47, $141-155$.

Nogué, J. (1988). «El fenómeno neorural». Agricultura y Sociedad, 47, 145-175.

- (2016). «El reencuentro con el lugar: nuevas ruralidades, nuevos paisajes y cambio de paradigma». Documents d'Anàlisi Geogràfica, 62 (3), 489-502.

Sabaté, A. (1992). «La participación de las mujeres en la dinámica social de zonas rurales desfavorecidas». Desarrollo local y medio ambiente en zonas desfavorecidas. Madrid: Ministerio de Obras Públicas y Transportes, 123-138.

Sampedro, R. (2009). "Escuchando la voz de las mujeres». Agricultura familiar en España 2009. Anuario de la Fundación de Estudios Rurales. Madrid: Unión de Pequeños Agricultores y Ganaderos, 92-102. 
Pallarès Barberà, M.; Tulla Pujol, A. F.; Pallarès Blanch, M. (2003). «Capital social i treball de les dones als Pirineus. El cas de l'Alt Urgell». Barcelona: Institut Català de la Dona. Generalitat de Catalunya.

Pallarès-Blanch, M. (2014). Estratègies de desenvolupament local rural, gènere i procesos innovadors en la nova ruralitat: l'aportació de les dones al desenvolupament, la innovació i la governança territorial a l'Alt Pirineu i Aran (Catalunya). Bellaterra: Universitat Autònoma de Barcelona. Departament de Geografia. Tesi doctoral.

SÁnchez Pardo, J. C. (2013). «Bases para el análisis geohistórico del poblamiento rural tradicional en Galicia». Boletín de la Asociación de Geógrafos Españoles, 62, 75-99.

Solana, M. (2000). Treball, mobilitat $i$ assentament de la població. Un cas comarcal: el Baix Empordà. Bellaterra: Universitat Autònoma de Barcelona. Departament de Geografia. Tesi doctoral.

Solé Figueras, A. (2014). Estrangers a la muntanya. El procés migratori i el procés d'assentament de la població estrangera a l'Alt Pirineu i Aran (2000-2012). Bellaterra: Universitat Autònoma de Barcelona. Departament de Geografia. Tesi doctoral.

Urry, J. (2004). "The "System" of Automobility». Theory, Culture and Society, 21 (4-5), 25-39.

Woods, M. (2007). «Engaging the global countryside: globalization, hybridity and the reconstitution of rural place». Progress in Human Geography, 31, 485-507.

- (2011). Rural. Londres: Routledge.

WIEST, K. (ed.) (2016). Women and migration in rural Europe. Labour markets, representations and policies. Basingstoke: Palgrave Macmillan. 